\title{
EVALUACIJA U NASTAVI ITALIJANSKOG JEZIKA: UTICAJ IZBORA TEHNIKA I NAČINA BODOVANJA NA ISHOD TESTIRANJA
}

\begin{abstract}
U ovom radu je predstavljeno istraživanje kojim su, kroz proces sastavljanja testa, njegove distribucije, evaluacije i analize dobijenih rezultata, kontekstualizovane i konkretizovane neke od teorijskih postavki iznetih u početnom poglavlju. Pažnja je bila usmerena samo na određene elemente ovog procesa: cilj nam je, naime, bio da ispitamo u kojoj meri metoda testiranja, odnosno izbor različitih tehnika i različit način bodovanja pilikom ocenjivanja istih elemenata lingvističko-komunikativne kompetencije, može uticati na krajnji ishod testiranja. U obradi dobijenih podataka korišćene su metode kvantitativne analize. Rezultati našeg istraživanja su pokazali da izbor različitih tehnika znatno utiče na postignuće, dok različiti načini bodovanja ne daju značajniju razliku u krajnjem ishodu testiranja.
\end{abstract}

Ključne reči: testiranje, tehnika, bodovanje, gramatička kompetencija, razumevanje pisanog teksta, leksička kompetencija

\section{Uvod}

Značaj evaluacije u celokupnom nastavnom procesu kao i nezanemarljiva društvena i politička uloga koju sve više poprima u današnjem društvu, doveli su do toga da ova tema kao oblast naučnog istraživanja konačno potvrdi ravnopravno mesto sa ostalim aspektima procesa nastave i ućenja stranog jezika. Važnu ulogu u razvoju jezičkog testiranja imalo je udaljavanje od doskora uobičajenog naglašavanja dokimološkog aspekta ove oblasti i preusmeravanje pažnje sa tehnika i psihometrijskih operacija na ono što je najbitnije, a to je predmet evaluacije i odgovor na pitanje šta to zapravo testiramo kada testiramo jezik (Barni, 2005: 32). U skaldu sa tim, u poslednjih nekoliko decenija istraživanja, razmišljanja, a ponekad i esperimentisanja koji su doveli do izrazitog kvalitativnog napretka gloto-

* draganamircic@pravnifakultet.rs 
didaktike kao samostalne nauke, oblast kojoj je prilikom istraživanja posvećivano najmanje pažnje, jesu upravo glotodidaktičke tehnike (Balboni, 1998: 1).

Nakon definisanja teorijskih okvira predmeta testiranja, pitanje izbora tehnika i načina bodovanja može se, možda, smatrati lakšim delom procesa sastavljanja testova, ali, jedan od ciljeva istraživanja koje će biti predstavljeno u ovom radu, bio je upravo da pokažemo da ne treba otići u krajnost i zanemariti ovaj završni, tehnički i praktični korak; pretpostavka od koje smo pošli bila je da pitanje izbora tehnika i načina bodovanja, kao nimalo lako i jednoznačno, može dovesti do značajno drugačijih rezultata testiranja. Istraživanje je bilo ograničimo na testiranje nekoliko elementa komunikativne kompetencije, a to su gramatička kompetencija, razumevanje pisanog teksta i leksička kompetencija. Ovakav izbor nije slučajan, a načinili smo ga jer nam je bila namera da se bavimo samo objektivnim tehnikama ${ }^{1}$ čija je primena u navedenim oblastima preporučljivija i validnija nego, na primer, u oblasti testiranja veština produkcije. Zadaci otvorenog tipa karakteristični za evaluaciju veštine pisanja ili govorenja, prema načinu bodovanja definišu se kao subjektivne tehnike kojima, sasvim prirodno, treba posvetiti posebnu pažnju i obazrivost prilikom ocenjivanja, dok nas korišćenje objektivnih tehnika naizgled lišava suočavanja sa brojnim nedoumicama. Upravo tu se krije još jedan od razloga zbog kojih smo se opredelili da u istraživanju budu zastupljene samo objektivne tehnike; cilj istraživanja bio je, između ostalog i to da ukažemo na to koliko je subjektivnog u objektivnom, odnosno koliko određene, neminovno subjektivne odluke predavača prilikom izbora, sastavljanja ili bodovanja objektivnih tehnika mogu promeniti završni ishod testiranja.

Pre nego što izložimo celokupan istraživački pristup, analizu rezultata, diskusiju i zaključke, u narednom poglavlju daćemo teorijski okvir našeg istraživanja.

\section{Neodređenost i jasnoća u jezičkom testiranju}

Momenat testiranja pred nas postavlja ne samo praktična pitanja izbora tehnika i izgleda testa, već nužno zahteva i neku vrstu odluke u po-

1 O vrstama tehnika prema načinu bodovanja više u poglavlju 5.4.2. 
gledu teorijskog pristupa predmetu testiranja, tj.jeziku, njegovoj prirodi i načinu na koji se usvaja i koristi. Mnogi autori saglasni su u mišljenju da je testiranje u oblasti društvenih nauka podložnije pravljenju grešaka, nego što je to, na primer, slučaj sa testiranjem u oblasti matematike i drugih prirodnih nauka (Mc Namara, 2000; Davies, 1990; Machetti, 2006). Ako je predmet testiranja jezik, mogućnost nepreciznosti se još više povećava.

Već pri prvom koraku, u pokušaju jasnog određivanja predmeta merenja i evaluacije, što je osnovni i logičan preduslov svakog ovakvog procesa, naići ćemo na poteškoće uviđajući da se jezik opire svakoj preciznoj definiciji, a bilo kakav pokušaj da se njegova neuhvatljiva priroda na neki način preoblikuje, suzi, ograniči, smesti u određene kalupe u cilju postizanja naučne preciznosti, oduzeo bi ono što čini samu suštinu jezika kao otvorenog, dinamičkog i multidimenzionalnog sistema. Njegova kreativnost, sociolingvistička varijabilnost, otvorenost za inovacije i stalna tenzija između poštovanja norme i odstupanja od nje u upotrebi, primoravaju nas da prilikom definisanja ostanemo neodređeni i krajnje fleksbilni (Barni, 2005: 40; Jafrancesco, Machetti, 2010: 147-148).

Sa druge strane, mora se prihvatiti i činjenica da čak ni najpreciznije naučno merenje nije apsolutno precizno, a njegovo primenjivanje na jezik koji je po prirodi promenljiv i neodređen, može samo doprineti uvećavanju te nepreciznosti. Teško je, dakle, očekivati da se može postići potpuno precizno merenje, a ono što bi trebalo da nas zadovolji jeste merenje preciznije od ostalih (Davies, 1990: 51-52).

Drugim rečima, opisanu složenost definisanja jezika i nedostatak preciznosti prilikom merenja ne bi trebalo tumačiti kao nepremostivu prepreku i odricanje vrednosti i neophodnosti jezičkog testiranja (Dimitrijević, 1999: 51). Važno je samo pronaći ravnotežu između neodređenosti (uncertainity) i jasnoće (explicitness), odnosno poželjnu meru u kojoj jezička komponenta ili priroda jezika treba da utiče na labavljenje psihometrijskih ograničenja koje nameće testiranje. Jezički test mora da kombinuje oba ova aspekta, što neizbežno vodi do tenzije između zahteva jezika i zahteva testiranja. Uspeh jezičkog testa zavisi upravo od usklađenosti ova dva zahteva koji mogu biti predstavljeni i kroz dinamički odnos između validnosti i pouzdanosti kao fundamentalnih obeležja svakog dobro osmišljenog testa (Davies, 1990: 9-10). 


\section{Validnost}

Test je validan ukoliko meri ono što treba da meri, ono što nam je bila namera da izmeri. Pored toga, on treba da predstavlja reprezentativni primer jezičkih sposobnosti koje su izabrane i definisane kao predmet merenja. Ukoliko, na primer, pred učenike postavimo zadatak da nakon što su saslušali neko predavanje, naprave o njemu kratak pisani rezime, njihovi pisani radovi ne mogu se iskoristiti za ocenjivanje pisane produkcije, jer je učenicima za ispunjenje zadatka bila neophodna i veština razumevanja. U slučaju da su razumeli samo mali deo onoga što su čuli, svakakao ne bi bili u stanju da uspešno napišu kratak pregled saslušanog predavanja. $\mathrm{Na}$ validnost testa može uticati i neusklađenost zadatka sa nivoom znanja učenika: ako za vežbu razumevanja pisanog teksta za učenike naprednog nivoa odaberemo tekst koji odgovara srednjem nivou, ne možemo dobiti valjane informacije o stvarnim sposobnostima učenika (Barni, 2000: 162).

\section{Pouzdanost}

Pouzdanost testa predstavlja njegovu doslednost, stabilnost; test je pouzdan ukoliko je u stanju da pruži iste ili približno iste rezultate i ako je primenjen u različitim momentima, a takođe i ako je ocenjen od strane različitih ocenjivača. U prvom slučaju pouzdanost će zavisiti pre svega od forme testa (recimo od jasnoće uputstava), od grafičkog aspekta (na primer od kvaliteta kopije) ili od uslova u kojima se test odvija (previše buke, loši tehnički uslovi). Još jedan od važnih faktora može biti i motivisanost učenika, ali njega ne možemo kontrolisati kao fizičke uslove ili formu testa. U drugom slučaju pouzdanost će potpuno zavisiti od onoga ko ocenjuje test. Problem ovde predstavljaju upravo subjektivni zadaci, tj. oni u kojima dodeljivanje poena zahteva sud ocenjivača, pa se manja ili veća mera subjektivnosti ne može isključiti, ali se koriščenjem određenih sredstava kao što su precizne skale sa kriterijumima ocenjivanja, edukovanje ocenjivača, obezbeđivanje komisije ocenjivača i sl. može doprineti maksimalnom smanjivanju nepouzdanosti (Barni, 2000: 161-162, 167-168).

\section{Procedura sastavljanja testa}

Osnovu svakog procesa sastavljanja testova ili ocenjivanja prikladnosti onih već postojećih, čine odgovori na pitanja vezana za svrhu, 
konstrukt, sadržaj i metodu testa (Mc Namara, 2000: 23-32; Sprugnoli, 2005:65-70).

\subsection{Svrha testa}

Ciljeve i sadržaj testa ne možemo odrediti pre nego što definišemo svrhu njegove upotrebe, tako da odgovor na ovo pitanje predstavlja polaznu tačku u realizaciji svakog testa. O podeli testova prema svrsi ne postoji potpuna saglasnost među stručnjcima, ali osnovna, i za nas najrelevantnija podela prema ovom kriterijumu razlikuje test dostignuća (achievement test) i test kompetencija (proficiency test) (V. Dimitrijević, 1999: 68-71; Barni, 2000: 163-166; Sprugnoli, 2005: 66-67; Mc Namara, 2000: 6-7)

Test dostignuća je striktno vezan za ciljeve i sadržaje određnog kursa jezika, a namera mu je da utvrdi u kojoj meri je učenik savladao obrađenu jezičku materiju; ovaj test, dakle, ne bi trebalo da obuhvata ono što nije predavano. Testovima dostignuća prikupljamo podatke u toku ili na kraju kursa, utvrđujući napredak postignut u odnosu na ranije postavljene ciljeve. Tako su testovi dostignuća na neki način vezani za prošlost, dok su testovi kompetencija okrenuti ka budućim situacijama jezičke upotrebe, a cilj im je da izmere opštu jezičku kompetenciju nezavisno od vrste kursa koji su kandidati možda pohađali. Sadržaj ovih testova ne može se, stoga, bazirati na nastavnom programu, ciljevima i metodama određenog kursa jezika - njegova struktura proističe iz odgovarajuće teorije o kompetenciji (Barni, 2000: 163-166; Mc Namara, 2000: 6-7).

Pošto smo utvrdili svrhu testiranja, trebalo bi da što podrobnije definišemo šta je ono što želimo da testiramo. Da bismo to postigli, pre nego što pređemo na pitanje konkretnog sadržaja testa, neophodno je da imamo teorijski konstrukt, odnosno model jezika i kompetencije koju nameravamo da merimo (Sprugnoli, 2005: 67).

\subsection{Konstrukt testa. Jedan model jezika i kompetencije: linvističko - komunikativna kompetencija po Zajedničkom evropskom okviru za žive jezike}

Pitanja preciznosti ili nepreciznosti testova i njihovih rezultata nemaju mnogo značaja ukoliko ih ne prate, tačnije, ukoliko im ne prethode razmišljanja o jeziku kao predmetu merenjai definisanje modela jezika i 
kompetencije (Machetti, 2006: 60-61). Dajući ličnu viziju istorije angloameričkog jezičkog testiranja, Dejvis (Davies) polemiše o tome da je evolucija u ovoj oblasti poslednjih decenja bila obeležena entuzijastičnim i nekritičkim prihvatanjem inovacija, što je vodilo ka neuravnoteženom posmatranju, prenaglašavanju jednog gledišta. On dalje objašnjava da privilegovanje definisanja jezika kroz njegovu upotrebu i varijetetsku raznovrsnost često dovodi do zapostavljanja forme i strukture koji su takođe značajni aspekti kompleksne jezičke prirode jezika. Otuda i njegov stav da i testovi, odražavajući uravnoteženo viđenje prirode jezika, treba da budu i analitički i integrativni (Davies, 2003: 356-357). Ova dva suprotna pola (analitičnost i integrativnost), mogu se povezati sa konceptima pouzdanosti i validnosti. Pouzdanost se povećava uvrštavanjem izolovanih zadataka u test, dok se validnost postiže približavanjem testa stvarnom životu, u ovom slučaju jeziku u upotrebi.

Baveći se praktičnim pitanjima tehnika, jezičkih veština i svrhe testa u svetlu njegove validnosti, Dejvis dalje tvrdi da najbolji testovi zahtevaju i proveravaju i lingvističku kompetenciju (za pouzdanost) i komunikativnu kompetenciju (za validnost) (Davies, 1990: 34-35, 38-40).

Ublažavanje razlika između ekstremnih viđenja prirode jezika nudi i model koji je usvojio ZEO - uz pomoć koncepta "lingvističko-komunikativne kompetencije" predlaže se prevazilaženje suprotnosti između zasebno posmatranih lingvističke i komunikativne kompetencije. Jezik, naime, nije shvaćen samo kao skup formalnih pravila, već kao sistem raznovrsnih jezičkih upotreba koje se ostvaruju u određenom društvenom kontekstu kojim su uslovljene. Stoga se i kompetencija definiše i kao "znanje", poznavanje jezičke strukture, ali i kao "umeće”, mogućnost upotrebe znanja u različitim kontekstima. (Barni, 2005: 37, ZEO, 2003: 17-19).

\subsection{Sadržaj testa}

Donošenje odluke o sadržaju predstavlja prvi praktičan korak u sastavljanju testa. Ta odluka treba posredno da odražava konstrukt testa, odnosno teorijski definisano viđenje jezika i jezičke upotrebe u testu, zajedno sa vezom između takve upotrebe jezika i njegove stvarne upotrebe $u$ različitim realnim kontekstima (Mc Namara, 2000: 25).

Budući da nema načina da se jezik u celosti opiše, prenese kroz nastavu i testira, potrebno je izabrati što reprezentativniji jezički uzorak koji će 
biti testiran. Dobar izbor konkretnih tekstova i zadataka u testu pitanje je od velike važnosti, jer će rezultati dobijeni merenjem jednog relativno malog jezičkog uzorka poslužiti kao osnova za donošenje zaključaka koji se odnose i na one sadržaje koji nisu testirani ili za predviđanja o sposobnosti komunikacije u stvarnim životnim situacijama (Dimitrijević, 1999: 55; Weir, 1990: 11). Izbor sadržaja zavisi i od vrste testa, pa će ovaj proces biti različit u slučaju testa dostignuća i testa kompetencija (Dimitrijević, 1999: 56).

Sadržaj testa dostignuća biće određen na osnovu nastavnog programa. Izbor se, dakle, vrši sa već postojeće liste obrađenih nastavnih jedinica uz poštovanje opšteg principa da sadržaj testa mora biti u proporciji sa sadržajem nastave. Drugim rečima, ukoliko je u toku kursa, semestra ili školske godine, više pažnje poklanjano govoru, a manje čitanju, to se na odgovarajući način mora reflektovati u testu. Postojanje silabusa i utvrđenih ciljeva nastave u znatnoj meri olakšava posao sastavljačima testova, ali ni u ovom slučaju oni nisu potpuno lišeni nedoumica. Naime, dok nastavni program obuhvata dosta širok jezički uzorak za čije je obrađivanje predviđen, na primer, čitav jedan semestar, sadržaj testa mora da bude prilično sveden i vremenski ograničen na jedan ili dva sata, a nekada i manje. To znači da se ni u ovoj fazi ne može izbeći izvesna (ali prihvatljiva) mera subjektivnosti pri konačnom odabiru jezičkog uzorka (Dimitrijević, 1999: 55-57; Davies, 1990: 2-3). Kako predlaže Dejvis, jedan od načina da se prevaziđu sumnje po pitanju validnosti sadržaja testa, jeste traženje potvrde sopstvenog izbora kroz stručno mišljenje i saglasnost drugih kolega (Davies, 1999: 26).

Biranje sadržaja testa kompetencija podrazumeva niz još složenijih odluka. Karakteristika ovakvih testova jeste da ne zavise od nekog određenog kursa i nastavnog programa, a da bi test bio sastavljen, neophodno je napraviti što sveobuhvatniju i detaljniju listu onih jezičkih jedinica koje će kandidatima biti neophodne kako bi mogli da ispune komunikativne zahteve situacija za koje se pripremaju (Dimitrijević, 1999: 56).

\subsection{Metoda testa}

Metoda testa se tiče načina na koji kandidati treba da reaguju na materijal i zadatke testa, posebno u smislu očekivanog formata odgovora, ali i načina na koji će ti odgovori biti pregledani i bodovani. Pri izboru metode 
testa treba biti veoma obazriv, jer te odluke mogu uticati na pravičnost zaključaka koje ćemo doneti o kandidatima; uzmimo za primer situaciju u kojoj treba da ocenimo da li su predavači, neizvorni govornici stranog jezika, u stanju da taj jezik koriste i kao medijum tokom svojih predavanja. Najneprirodnije, ali i administrativno najpraktičnije rešenje bilo bi da se kandidatima dâ pisani zadatak koji bi od njih zahtevao da opišu na koji način bi, na primer, svojim učenicima dali uputstva za određenu aktivnost. Druga mogućnost bila bi usmena simulacija davanja uputstava kroz roleplay, a najautentičniji, ali i najskuplji i najkompleksniji način svakako bi bio posmatranje jezičke delatnosti predavača u toku pravog časa, ili, još bolje, u toku nekoliko časova. Moguće je da bi na kraju različiti formati zadataka doveli do drugačijih zaključaka o sposobnostima kandidata (Mc Namara, 2000: 26-29).

Kao što smo videli, visok stepen autentičnosti odgovora, podrazumeva, nažalost, i visok stepen nepraktičnosti testiranja, pa je prihvatanje veće ili manje mere artificijelnosti testa i korišćenje određenih konvencionalnih i potencijalno neautentičnih tehnika neophodno.

\subsubsection{Izbor tehnika ${ }^{2}$}

Izbor tehnika zavisiće i od toga koje aspekte jezičke sposobnosti ili znanja želimo da poverimo (Barni, 2000: 169). Tako se, na primer, tehnika višestrukog izbora obično povezuje sa testiranjem poznavanja gramatičkih pravila ili proverevanjem razumevanja pisanog ili usmenog teksta, kada se uobičajeno koristi i dvočlani izbor (tačno/pogrešno). I poznavanje leksičkih sadržaja često se proverava pitanjima sa mogućnošću višestukog izbora prilikom odgovora ili pak povezivanjem reči sa mogućim definicijma. Sve prethodno navedene tehnike spadaju u grupu zadataka sa unapred ponuđenim odgovorima, a sve što kandidat treba da uradi u ovom slučaju jeste da izabere onaj pravi. Nešto zahtevniji, ali i autentičniji jesu zadaci otvorenog tipa čija je prednost $u$ tome što u znatno manjoj meri sputavaju kandidate, istovremeno umanjujući mogućnost slučajnog pogađanja

2 Pod pojmom tehnike testiranja podrazumevamo oblik podsticaja (stimulusa) i reakcije učenika. Prema najjednostavnijoj podeli stimulusi i reakcije mogu biti usmeni i pisani, što podrazumeva niz opcija kao što su reč, rečenica, pitanje, monolog, interaktivni dijalog, esej, opisivanje, kratak odgovor, definisanje termina itd (Brown, 2004: 51). 
tačnog odgovora. U ovu grupu spadaju, na primer, pitanja koja zahtevaju kratke pisane ili usmene odgovore. Zadaci otvorenog tipa, poput eseja i intervjua, često se koriste prilikom testiranja produktivnih veština, kada je potrebno je doneti niz odluka o sadržaju i formatu stimulusa, o dužini i obliku odgovora, ali i o načinu bodovanja (Mc Namara, 1990: 30-31).

\subsubsection{Bodovanje}

$\mathrm{Na}$ osnovu načina ispravljanja i bodovanja, testovi i zadaci se mogu podeliti na objektivne i subjektivne. U objektivnom testu, sačinjenom od zadataka sa unapred ponuđenim odgovorima, tačan odgovor je definisan još u momentu sastavljanja zadatka, pa ispravljanje i bodovanje ne zahtevaju sud onoga ko ocenjuje. Za ocenjivanje ovakve vrste testova nije čak neophodno ni postojanje ocenjivača - tačnost odgovora može se proveriti i putem kompjutera - pa su pouzdanost i lakoća pregledanja osnovne prednosti objektivnih testova. Treba, međutim, naglasiti da je objektivnost $u$ ovom slučaju vezana isključivo za momenat ispravljanja i bodovanja, dok je pripremanje zadatka (izbor određene tehnike, teksta, način formulacije i sl) ipak obeleženo subjektivnošću.

Pregledanje subjektivnih testova sastavljenih od zadataka otvorenog tipa zahteva prisusustvo ocenjivača kao i njegov sud o ispravnosti ili stepenu ispravnosti datog odgovora. Sada već postoji saglasnost o tome da se objektivni testovi koriste pre svega za proveravanje receptivnih veština, dok se subjektivni testovi, koji ne sputavaju kreativnost jezika, primenjuju prilikom testiranja produktivnih veština pisanja i govorenja. S obzirom na to da rezultati testova često mogu poslužiti kao osnova za donošenje važnih odlluka o budućnosti kandidata, neophodno je težiti što većoj objektivnosti, kako u procesu sastavljanja zadataka (pre svega u slučaju objektivnih testova), tako i u momentu ocenjivanja (naročito u slučaju subjektivih testova) (Barni, 2000: 167-170; ZEO, 2003: 211-263).

\section{Istraživanje $i$ istraživački pristup}

U istraživanju je učestvovao 31 polaznik kursa italijanskog jezika koji organizuje Italijanski kulturni centar, a sprovedeno je u toku decembra 2018. godine. Iako u tri različite grupe, svi polaznici pohađali su isti nivo (B1.1), koristili isti udžbenik (Espresso 2) i od početnog nivoa učenja ita- 
lijanskog jezika do momenta istraživanja pratili isti program predstavljen približno ujednačenim ritmom i metodologijom. Pre nego što je započet rad na 8. lekciji koja je bila uži predmet testiranja, pripremljen je isti dodatni materijal za sve predavače sa ciljem da se u najvećoj mogućoj meri ujednače sadržaji koji će se obrađivati i predupredi mogućnost uvođenja novih ili različitih jezičkih elemenata u različitim grupama. Svi ispitanici su podvrgnuti testiranju u istom trenutku, odnosno nakon završene 8 . lekcije. Svrha testa je, dakle, bila da se utvrdi u kojoj meri su učenici savladali određene elemente jezičke materije obrađene u jednoj lekciji, pa je jasno da se radilo o periodičnom testu dostignuća, što, kao forma, za ispitanike nije predstavljalo novinu.

Vodeći se principom da testiramo ono što predajemo, možemo reći da je konstrukt testa praktično određen samim udžbenikom baziranim na modernim metodološkim principima usklađenim sa Zajedničkim evropskim okvirom za žive jezike, pa je model jezika i kompetencija koje želimo da testiramo poistovećen sa lingvističko-komunikativnom kompetencijom koju nam nudi ovaj značajan dokument. Ističemo još jednom da je za potrebe našeg istraživanja test sveden na objektivne tehnike, dok bi ispitivanje celokupne komunikativne kompetencije zahtevalo i niz zadataka koji pripadaju subjektivnim tehnikama. Prihvatajući stanovište da dobar test treba da bude i analitički i integrativn (Davies, 2003: 356-357), a oslanjajući se i na izbor zadataka u testovima u okviru udžbenika koji su ispitanici koristili, test koršćen kao instrument istraživnja sadrži tradicionalne tehnike koje ostaju na formalnom nivou strukture jezika, ali koje su, sa druge strane, precizne u određivanju usvajnja izolovanih elemenata gramatičke kompetencije, ali i tehnike koje nisu lišene komunikativnih ciljeva, pa su od ispitanika zahtevale sagledavanje teksta u celini, aktiviranje strategija razumevanja, odnosno integrativni pristup rešavanju zadatka.

Budući da se radilo o testu dostignuća, pitanje izbora sadržaja testa nije predstavljalo veliki problemjer je on već određen samim silabusom, a pošto se radilo o samo jednoj lekciji i dosta suženom jezičkom uzorku, nije bilo velikih nedoumica ni prilikom izbora.

Konkretno realizovan test ${ }^{3}$ sastojao se od šest zadataka, a ispitivani su sledećim redom: gramatička kompetencija (poznavanje oblika i upotrebe 
futura), razumevanje pisanog teksta (gramatičke strukture, leksika i jezičke funkcije usklađene sa obrađenim sadržajima) i leksička kompetencija (leksika vezana za posao). Za svaki od ovih elemenata u testu su postojala dva zadatka predstavljena dvema različitim tehnikama; jedan je, prema našoj pretpostavci bio lakši, a drugi teži za učenike. Zadaci su raspoređeni tako da je polovina ispitanika radila test u kome su prvi, drugi i treći zadatak predstavljali lakšu varijantu testa (u daljem tekstu označenu kao deo A), a četvrti, peti i šesti zadatak težu varijantu testa (u daljem tekstu označenu kao deo B). Drugoj polovini ispitanika dat je test sa obrnutim rasporedom zadataka, a cilj je bio da se ravnomerno rasporedi eventualno dodatno otežavanje zadataka koje bi proisticalo iz položaja koje ti zadaci zauzimaju u testu. Na primer: iako smo mi neki zadatak ocenili kao lakši, ukoliko se nalazi na poslednjem mestu u testu, on bi za ispitanike, usled manjka koncentracije ili motivacije, mogao da predstavlja veći problem od nekog zadatka koji je svrstan među lakše. Vreme rađenja testa bilo je ograničeno na 30 minuta.

Konkretan izbor tehnika za koje smo se opredelili je sledeći:

1. Za ispitivanje gramatičke kompetencije i u slučaju lakše i u slučaju teže varijante odabrana je tehnika popunjavanja, s tim što je u prvom slučaju zadatak realizovan na nivou rečenica, a glagoli koje je trebalo staviti u oblik futura dati su u zagradi. U drugom slučaju se radi o zadatku na nivou teksta sa glagolima koji su dati iznad teksta pomešanim redosledom. Radi mogućnosti što pouzdanijeg poređenja, prilikom sastavljanja zadataka vođeno je računa o tome da u oba zadatka bude jednaka zastupljenost lica $\mathrm{i}$ isti broj slučajeva u kojima je lice eksplicitno dato, da bude prisutan isti broj pravilnih glagola $\mathrm{i}$ isti broj glagola sa istim tipom nepravilnosti. Ovakva postavka zadataka imala je za cilj da nam omogući da eventualnu manju uspešnost ispitanika u drugoj vrsti zadatka tumačimo na osnovu višeg nivoa kompleksnosti same tehnike, što konkretno znači da je ispitanicima u ovom slučaju za uspešno rešavanje zadatka bio potreban viši stepen posedovanja veštine razumevanja nego u prvom tipu zadatka. Zadatak koji ispituje gramatičku kompetenciju u delu B delimično je preuzet iz udžbenika Progetto italiano 1 (Magnelli, Marin, 2010: 47).

2. Za ispitivanje razumevanja pisanog teksta u slučaju lakše verzije odabrana je tehnika povezivanja pitanja i odgovora, dok je u slučaju teže varijante naš izbor bio komplesnija verzija tehnike sređivanja dijaloga u kojoj nije unapred dat redosled replika nijednog od dva sagovornika, a 
zadatak je delimično preuzet iz udžbenika Da zero a cento (Ciulli, Proietti, 2005: 46).

3. Za ispitivanje leksičke kompetencijeu slučaju lakše varijante opredelili smo se za tehniku višestrukog izbora na nivou teksta, a u slučaju težeg zadatka odabrana je ponovo tehnika popunjavanja realizovana na nivou rečenice. Zadatak iz dela A delimično je preuzet iz udžbenika Progetto italiano 2 (Ruggieri, Magnelli i dr., 2013: 28-29).

Naglašavamo da su sve tehnike izabrane iz širokog repertoara tehnika koje su korišćene u toku kursa, pa su ispitanicima od ranije poznate. Pre nego što je ispitanicima dat test, predavači su postigli intersubjektivnu saglasnost o validnosti zadataka, o stepenu kompleksnosti izabranih tehnika, o izboru sadržaja prisutnog u zadacima, o ujednačenosti gramatičke i leksičke kompleksnosti u parovima lakših i težih zadataka, o adekvatnosti distraktora, rečenica ili tekstova upotrebljenih za kontekstualizaciju gramtičkih i leksičkih elemenata.

Prilikom izbora načina bodovanja, kako bismo se pozvali na realnu situaciju, opredelili smo se da on bude preuzet iz periodičnih testova dostignuća koje su ispitanici već radili u toku ovog i prethodnih kurseva, a koji su jednaki za sve polaznike istih nivoa koji pohađaju kurseve u Italijanskom kulturnom centru. Prema ovom načinu bodovanja, svaki tačan odgovor nosio je 1 poen. Prilikom bodovanja višestrukog izbora nisu predviđeni negativni poeni, jer ispitanici u toku dosadašnjih kurseva uglavnom nisu bili upoznati sa ovakvim načinom bodovanja. Intersubjektivna saglasnost između predavača postignuta je i po pitanju bodovanja, dobijanjem potvrde da je ovakav način bodovanja bio najčešće zastupljen u testovima dostignuća koje su ispitanici do tada radili.

Uz pretpostavku da će različit izbor tehnika dovesti do značajno drugačijih rezultata testiranja, želeli smo da ispitamo i u kojoj meri drugačiji način bodovanja može uticati na ujednačavanje rezultata između dela A i dela $B$, a naša pretpostavka je bila da drugačiji način bodvanja može dovesti do ujednačavanja postignutih rezultata. Stoga smo u fazi analize rezultata testova uveli i drugi način bodovanja promenivši broj bodova u onim zadacima gde je to, prema našem sudu, imalo smisla:

- u težoj varijanti zadatka koji ispituje gramatičku kompetenciju, za svaki tačan odgovor umesto 1 , predvideli smo 1,5 poen, pri čemu 0,5 poena ispitanik dobija ukoliko je glagolu odredio tačno mesto. 
- u težoj varijanti zadatka koji ispituje leksičku kompetenciju, predviđeno je da svaki tačan odgovor nosi 1,5 poen kako bi se napravila razlika u odnosu na zadatak sa višestrukim izborom koji zahteva samo pasivno poznavanje datih leksičkih elemenata.

- u težoj varijanti zadatka koji ispituje razumevanje pisanog teksta odlučili smo se da bodujemo i svaku ispravnu sekvencu dijaloga, a ne samo čitav niz.

\section{Rezultati istraživanja}

Za analizu razlika u postignuću ispitanika na testu iz italijanskog jezika u zavisnosti od vrste korišćenih tehnika i načina bodovanja njihovih odgovora korišćen je t-test za ponovljena merenja. Na ovu analizu smo se odlučili zbog toga što je za svakog ispitanika uzimano u obzir više mera koje su međusobno poređene. Tabelarni prikaz rezultata obrađenih ovom metodom nalazi se u prilogu II, tabele 1 i 2.

\subsection{Tehnike}

U ovom delu predstavićemo rezultate poređenja postignuća u delu A i u delu B bodovanom na prvi način (u daljem tekstu B1). Ukoliko nema razlika u bodovanju, što znači da poredimo samo različit izbor tehnika i njegov uticaja na skor, analiza rezultata pokazuje da ima statistički značajne razlike u prikazu postignuća ispitanika prilikom davanja gramatičkih zadataka iz A dela i B1 dela $(t=2,256 ; d f=30, p=0,31)$. Konkretnije gledano, ispitanici imaju veće prosečne skorove na zadacima koji ispituju gramatičku kompetenciju u delu A $(\mathrm{M}=0,71)$ nego u delu B1 $(\mathrm{M}=0,62)$. Prevedeno pojmovima bodovanja, to znači da su u proseku za 0,9 poena bili bolji u delu A nego u delu B1.

Rezultati dalje pokazuju da statistički još značajnija razlika u prikazu postignuća prilikom davanja zadataka iz A i B1 dela postoji kada je u pitanju razumevanje pisanog teksta $(t=5,884 ; \mathrm{df}=30 ; \mathrm{p}=0,00)$. Naime, prosečan skor razumevanja pisanog teksta u oviru A dela je $0,88(\mathrm{M}=0,88)$, dok on u B1 delu iznosi $0,61(\mathrm{M}=0,61)$. Prevedeno pojmovima bodovnja, to znači da su ispitanci u zadacima koji ispituju razumevanje pisanog teksta ostvarivali u proseku 2,7 poena više u delu A nego u delu B1. 
I analiza trećeg para zadataka koji su ispitivali leksičku kompetenciju u delu A i delu B1 ukazuje na značajnu statističku razliku u postignuću $(\mathrm{t}=5,080 ; \mathrm{df}=30 ; \mathrm{p}=0,00)$. I ovoga puta ispitanici imaju veće prosečne skorove u delu A $(\mathrm{M}=0,67)$ nego u delu $\mathrm{B} 1(\mathrm{M}=0,41)$. Konkretnije, to znači da su ispitanici u proseku za 2,6 poena bili bolji u delu A nego u delu B1.

\subsection{Način bodovanja}

Ukoliko poredimo postignuće u delu A i delu B bodovanom na drugi način (u daljem tekstu B2), analiza rezultata pokazuje da ne postoji statistički značajna razlika u skoru postigntom u delu A i delu B2 kada se radi o zadacima koji ispituju gramatičku kompetenciju $(\mathrm{t}=0,802$; $\mathrm{df}=30 ; \mathrm{p}=0,429)$. $\mathrm{U}$ delu A prosečan skor koji su ispitanici postizali je 0,71 $(\mathrm{M}=0,71)$, dok on u delu B2 iznosi $0,68(\mathrm{M}=0,68)$, pa je razlika u postignću samo 0,3 poena u korist dela A. Analiza para zadataka koji su ispitivali razumevanje pisanog teksta pokazuje da je viši prosečan skor potignut $u$ delu $A(M=0,88)$ nego u delu B2 $(M=0,65)$. što konkretno znači da su ispitanici na zadatku koji je ispitivao razumevanje pisanog teksta postizali u proseku 2,3 poena više u delu A nego u delu B2 i da postoji statistički značajna razlika u postignuću između ova dva zadatka $(\mathrm{t}=5,921 ; \mathrm{df}=30$; $\mathrm{p}=0,00)$.

Kada se radi o ispitivanju leksičke kompetencije, rezultati nam govore da nema statistički značajne razlike u skorovima koje su ispitanici dobijali u zavisnosti od dva načina bodovanja $(t=0,703 ; d f=30 ; p=0,487)$. Naime, u okviru leksičkih zadataka, ispitanici su ostvarili u proseku iste rezultate u delu $\mathrm{A}(\mathrm{M}=0,66)$ i u delu $\mathrm{B} 2(\mathrm{M}=0,61)$, uz razliku u skoru od samo 0,5 poena.

\subsection{Procenat uspešnosti}

$\mathrm{Na}$ osnovu deskriptivne statistike izračunat je ukupan procenat uspešnosti ispitanika u odnosu na maksimalan broj poena za deo A, deo B1 i deo B2 (Prilog II, tabela 3). Rezultati pokazuju da je u delu A procenat uspešnosti iznosio $78 \%$, u delu B1 ta vrednost je bila 56\%, dok je u delu B2 procenat uspešnosti iznosio $60 \%$. Istim postupkom izračunat je i procenat uspešnosti za svaki zadatak posebno. U delu A u zadatku koji je ispitivao gramatičku kompetenciju procenat uspešnosti je $71 \%$, u zadatku 
koji ispituje razumevanje pisanog teksta, taj procenat je $88 \%$, a u leksičkom zadatku $67 \%$. U delu B1 procenat uspešnosti u zadatku koji ispituje gramatičku kompetenciju je $62 \%$, u zadatku razumevanja pisanog teksta $61 \%$, a u zadatku koji ispituje leksičku kompetenciju 41\%. U delu B2 u gramatičkom zadatku procenat uspešnosti je $68 \%$, u zadatku razumevanja pisanog teksta $69 \%$, a u leksičkom zadatku $41 \%$.

\section{Diskusija}

Posmatrajući najpre razliku u procentualno izraženom postignuću između dela A i dela B1, koji su, podsećamo bodovani na isti način, zaključujemo da je naša početna pretpostavka potvrđena i da izbor tehnika zaista može u znatnoj meri uticati na krajnji ishod testiranja. Rezultati poređenje parova zadataka iz dela A i dela B1 ukazuju na to da najmanja razlika u poenima postoji u paru zadataka koji su ispitivali gramatičku kompetenciju. Objašnjenje za to možda možemo pronaći u postupku koji je prema našem iskustvu uobičajen prilikom sastavljanja testa, a sledili smo ga i u ovom konkretnom slučaju: vođeno je, naime, računa o tome da kontekstualizacija pojednačnih stavki u gramatičkom zadatku iz dela B1 bude takva da nivo kompleksnosti leksičkih i sintaksičkih elemenata ne blokira razumevanje celokupnog teksta. Cilj je, dakle, da i u integrativnom zadatku koji od ispitanika zahteva kombinovanje više kompetencija, pažnja bude usmerena prvenstveno na ono što želimo da testiramo, a to je u ovom slučaju bila gramatička kompetencija. Možemo, onda, zaključiti da izbor jedne ili druge tehnike popunjavanja (na nivou rečnice sa glagolima u zagradi i na nivou teksta bez datog redosleda glagola), ukoliko su pažljivo sastavljene ili odabrane, u krajnjem rezultatu testiranja ne moraju dovesti do prevelike razlike, ali je ona, ipak, i dalje statitistički značajna.

Posmatranjem rezultata dobijenih poređenjem para zadataka koji su testirali razumevanje pisanog teksta, kao i procentualno izražene uspešnosti u jednom i drugom zadatku, utvrdili smo da upravo ovde postoji najveća razlika u postignuću. Prilikom sastavljanja zadataka vođeno je računa o tome da leksička i gramatička kompleksnost u oba zadatka budu ujednačene, ali je svesno odabrana najteža verzija tehnike sređivanja dijaloga, pa za nas ne predstavlja iznenađenje nalaz o tome da je tehnika izabrana $u$ delu B1 (sređivanje dijaloga bez delimično datog redosleda replika) jedno- 
stavno za ispitanike bila znatno teža od tehnike koju smo koristili u delu A (povezivanje pitanja i odgovora). Namera nam je bila da ovakvim izborom tehnika sa tako očiglednom razlikom u kompleksnosti istaknemo koliko velika može biti razlika u postignuću prilikom izbora različitih tehnika, a rezultati su ovu pretpostavku potvrdili. Ono što bi se moglo izdvojiti kao preporuka na osnovu ovog nalaza jeste da, ukoliko želimo komparabilne rezultate dobijene na različitim testovima, kada se radi o ovom tipu zadataka razumevanja pisanog teksta, izbegavamo korišćenje ove dve vrste tehnika. U potrazi za srednjim rešenjem mogli bismo da koristimo i jednostavnije vezije tehnike sređivanja dijaloga, na primer sa sređenim redosledom replika jednog sagovornika, ili sa više unapred datih pozicija za pojedine replike, uz pretpostavku da bi rezultati dobijeni korišćenjem ove tehnike bili ujednačeniji sa rezultatima tehnike povezivanja pitanja i odgovora sa jedne strane i teže verzije tehnike sređivanja dijaloga sa druge srane. Drugi način ujednačavanja postignuća bio bi eventualna promena načina bodovanja o čemu će biti reči u nastavku teksta.

Značajna je razlika u postignuću i u okviru zadataka koji su ispitivali leksičku kompetenciju. Ovaj rezultat ponovo potvrđuje da je usled izbora različitih tehnika testiranja, kao što je i očekivano, zadatak iz dela A za ispitanike bio znatno teži od zadatka iz dela B1. Ujednačavanje postignuća u ovom slučaju možda bi se moglo postići uprošćavanjem zadatka iz dela B1 tako što bismo, na primer, dodali početna slova traženih reči, a svakako bi imalo smisla i razmisliti o drugačijem bodovanju.

Rezultati analize podataka koji se tiču drugačijeg načina bodovanja $\mathrm{u}$ delu B2 i njihovog poređenja sa rezultatima iz dela A i dela B1, nisu u potpunosti potvrdili našu početnu pretpostavku po kojoj bi drugi način bodovanja mogao dovesti do značajnog ujednačavanja postignutih rezultata u delu A i u delu B2. Ukupan procenat uspešnosti u delu B2 samo je neznatno viši od procenta uspešnosti u delu B1, iz čega sledi da je, u okvirima našeg istraživanja, izbor tehnike više uticao na krajnji ishod testiranja nego način bodovanja.

Posmatrano zasebno, što se tiče gramatičkih zadataka došlo je do ujednačavanja postignuća, ali i zahvaljujući tome što razlika u postignuću i u slučaju prvog načina bodovanja nije bila prevelika. Budući da se ipak radilo o statistički značajnoj razlici, savet koji može proisteći iz prethodno datih nalaza jeste da se tehnika popunjavanja u kojoj glagoli nisu ponuđeni 
u pravilnom rasporedu ipak boduje sa $50 \%$ više poena nego tehnika popunjavanja u kojoj su glagoli dati u zagradi.

Što se tiče para zadataka koji su proveravali razumevanje pisanog teksta, drugi način bodovanja nije doveo do značajnijeg ujednačavanja postignuća. Stoga je, u ovom slučaju, ukoliko nam je namera da koristimo zadatke koji bi dali ujednačene rezultate, ipak bolje izabrati tehnike ujednačenije kompleksnosti nego pribeći drugačijem načinu bodovanja.

I na kraju, ni u slučaju leksičkog zadataka nema razlike u postignuću u zavisnosti od dva načina bodovanja, a uvideli smo da je ovakav rezultat proistekao iz činjenice da prilikom drugog načina bodovanja nismo uveli skaliranje, odnosno mogućnost prihvatanja delimično tačnih odgovora. Budući da je, onda, broj tačnih odgovora ostao isti prilikom prvog i drugog načina bodovanja, procentualno izraženo, i usupešnost je ostala ista. Eventualna prednost predviđanja većeg broja poena za teži zadatak u ovom slučaju mogla bi biti samo pružanje psihološke satisfakcije zbog osvajanja većeg broja poena. Ipak, mišljenja smo da bi primena skaliranja prilikom bodovanja, na primer uvođenjem negativnih poena u zadatku sa višestrukim izborom, mogla dovesti do ujednačavanja postignutih rezultata u slučaju poređenja tehnike višestrukog izbora i tehnike popunjavanja. Zanimljivo bi, možda bilo i ispitati na koji način se, u okviru jednog testa, određuje odnos bodovanja zadataka koji testiraju različite elemente lingvističko-komunikativne kompetencije.

\section{Zaključak}

U radu smo predstavili istraživanje koje polazi od pretpostavke da izbor različitih tehnika i različit način bodovanja prilikom jezičkog testiranja mogu znatno uticati na krajnji ishod tog testiranja. Izloženi rezultati su pokazali da je naša početna pretpostavka potvrđena što se tiče izbora različitih tehnika, gde postoje statistički značajne razlike u postignuću u zavisnosti od vrste i stepena kompleksnosti izabrane tehnike. Sa druge strane, na osnovu rezultata našeg istraživanja, različiti načini bodovanja ne daju značajniju razliku u krajnjem ishodu testiranja.

Istaći ćemo, na kraju i to, da svrha ovog rada nije bila da pruži gotova rešenja koja bi važila za svaku situaciju, niti da sugeriše upotrebu jedne ili izbegavanje druge tehnike prilikom svake vrste testiranja ili na svim 
nivoima učenja jezika. Uz svest o tome da proces ocenjivanja u oblasti stranog jezika nužno iziskuje izvesno labavljenje strogih pravila, prihvatanje nepreciznosti i odustajanje od potrebe da uvek i sve bude potpuno razjašnjeno, namera nam je bila da ukažemo na značaj izbora tehnika i načina bodovanja prilikom ocenjivanja i istaknemo potrebu da se tom pitanju prilazi sa što manje prizvoljnosti, sa posebnom pažnjom i jasnim stavom o tome iz kojih razloga i sa kojim ciljem koristimo određenu tehniku ili način bodovanja. Nadamo se, takođe, da tema kojom smo se bavili zavređuje da bude ispitana i na širem uzorku ili uz više parametara.

\section{LITERATURA}

Balboni, P. E. (1998). Tecniche didattiche per l'educazione linguistica. Torino: Utet

Barni, M. (2000). La verifica e la valutazione. In De Marco, A. (ed), Manuale di Glottodidattica, Insegnare una lingua straniera (pp. 155-174). Roma: Carocci editore,

Barni, M. (2005). La valutazione delle competenze linguistico-comunicative in L2. In Vedovelli, $\quad$ M. ( ed), Manuale della certificazine dell'italiano L2 (pp. 29-45). Roma: Carocci editore

Brown, D. (2004). Language Assessment. Principles and Classroom Practices. London: Longman

Davies, A. (1990). Principles of Language Testing. Oxford: Basil Backwell

Davies, A. (2003). Three heresies of language testing research. Language Testing, 20, 355-368

Dimitrijević, N. (1999). Testiranje u nastavi stranih jezika, treće prerađeno i dopunjeno izdanje. Beograd: Zavod za udžbenike i nastavna sredstva

Jafrancesco, E., Machetti, S. (2010). Valutare le competenze linguistico-comunicative in ambito disciplinare. In Lugarini, E. (ed), Valutare le competenze linguistiche (pp. 145-159). Milano: Franco Angeli

Machetti, S. (2006). Misurare e valutare la lingua. Precisione dello strumento versus vaghezza dell'oggetto? Educazione permanente, I nuova serie, 59-99

McNamara, T. (2000). Language Testing. Oxford: Oxford University Press

Sprugnoli, L. (2005). Il processo e le procedure di valutazione. In Vedovelli, M. (ed), Manuale della certificazine dell'italiano L2 (pp. 61-70). Roma: Carocci editore 
Weir, C. J. (1990). Communicative language testing. London: Prentice Hall

Zajednički evropski okvir za žive jezike. (2003). Podgorica: Ministarstvo prosvjete i nauke

\title{
Izvori
}

Balì, M., Rizzo, G. (2014). Espresso 2, Corso di italiano (libro dello studente ed esercizi). Firenze: Alma Edizioni

Ciulli, C., Proietti, A. (2005). Da zero a cento. Firenze: Alma edizioni

Magnelli, S., Marin, T. (2010). Progetto italiano 1 (quaderno degli esercizi e delle attività video). Roma: Edilingua

Ruggieri, L., Magnelli, S., Marin, T. (2013). Progetto italiano 2 (quaderno degli esercizi e delle attività video). Roma: Edilingua

\section{Dragana Mirčić Panić}

\section{ASSESSMENT IN THE ITALIAN LANGUAGE TEACHING: INFLUENCE OF THE TECHNIQUE CHOICES AND TYPE OF SCORING ON THE TESTING RESULTS}

\begin{abstract}
Summary
This essay presents a resaerch which, trough the process of test design, its distribution, assessment and the analysis of the obtained results, contextualizes and specifies some of the theoretical standpoints stated in the introduction chapter. The attention was directed only to certain elements of this process: our aim was ti investigate to what extent does the testing method, i.e. the choice of different techniques and different types of scoring used in the grading of the same elements of the communicative language competence, affects the final result of testing. Quantitative analysis was used in the resulting data processing. The results of our research have shown that the choice of different techniques significantly affects the outcome, while different types of scoring do not lead to important variations in the final testing results.
\end{abstract}

Keywords: testing, technique, scoring, grammar competence, reading comprehension, lexical competence 


\section{Prilog I}

A

\section{Completa con i verbi al futuro:}

/10

1. Purtroppo, mia moglie ed io non (1) (potere) venire alla festa.

2. Domani i bambini (2)

3. Chiara, quando (3) (dovere) andare a letto presto. bene il computer?

4. Ragazzi, domani (4) (imparare) finalmente a usare

5. Noi (5) (vedere) Laura?

6. Dopo la festa, gli amici (6) (stare) al mare per due settimane. re in ordine la casa.

7. Non (7) (aiutare) Stefano a mette-

8. Un giorno (8) (essere, io) a Milano prima del 5 settembre.

9. Mamma, ti prometto che da grande io (9) (comprare) anch'io una Ferrari!

re) un famoso architetto!

10. L'anno prossimo Marco (10) (diventa-

\section{Collega le domande alle risposte:} $1 \mathbf{1 0}$

1. Pensi sempre di andare a vivere all'estero?

2. Direttore, posso parlarLe?

3. Quando andrà a vivere da sola Cristina?

4. Hai ancora un lavoro dipendente?

5. Come andrai a Roma?

6. Maria è tornata da Cuba?

7. Avete già deciso qualcosa per Natale?
A No, già da un anno lavoro in proprio.

B Sì, ma aspetto ancora la ris posta del capo.

C Se sabato farà bel tempo, andremo al mare.

D No, l'anno scorso è andato in pensione.

E Non mi dica che vuole un aumento?!

F Sì, se imparerò bene l'inglese, cercherò lavoro negli Stati Uniti.

G Appena troverà un lavoro fisso. 
8. Cosa volete fare questo fine settimana?

9. Hai già chiesto il giorno libero per il compleanno di tua moglie?

10. Tuo padre lavora ancora?
$\mathbf{H}$ Volevo andarci in aereo, ma non ho trovato il biglietto, probabilmente prenderò il treno.

I Quest'anno faremo un viaggio, abbiamo già prenotato tutto.

J Sì, ieri ho parlato con lei, è rimasta molto impressionata.

3. Scegli la parola giusta e completa la lettera che Federico Blasi ha inviato alla Starcom Italia, un'azienda di telecomunicazioni che cerca un nuovo direttore del personale: 17

In riferimento al vostro annuncio apparso su Cercolavoro, mi permetto di presentare risposta/lettera/domanda per l'impiego in questione.

Come potete vedere, sono in possesso di molti dei documenti/requisiti/titoli di studio da voi richiesti. Mi sono laureato in Economia e Commercio a pieni voti presso la Normale di Pisa. Parlo correntemente l'inglese e il tedesco e ho inoltre delle ottime conoscenze informatiche.

Non ho, è vero, una grande esperienza/preparazione/conoscenza lavorativa: il mio primo lavoro l'ho avuto due anni fa come Responsabile Relazioni Estere presso la Interdata di Milano, dove lavoro ancora oggi a tempo intero/pieno/ definito. Si tratta però di un'azienda che non offre serie possibilità di carriera, e questa è la ragione principale per cui ho deciso di rispondere al vostro annuncio. In attesa di una vostra gentile risposta, rimango a vostra disponibilità/attenzione/disposizione per un eventuale incontro e do/porgo/spedisco i miei più cordiali saluti.

Federico Blasi

In attaccato/inviato/allegato: curriculum vitae

B

1. Completa con i seguenti verbi al futuro:

B1: 110

B2: $\quad 115$

rimanere, tornare, vivere, avere, andare, essere, fare, aprire, lavorare, essere 
Paolo: Ragazzi, cosa dopo la laurea?

Giovanni: Io forse nell'ufficio di mio zio.

Paolo: E tu Riccardo, a casa dai tuoi?

Riccardo: Sì, con i miei genitori; loro contenti perchè finalmente un figlio laureato. Purtroppo, con la mia laurea non facile trovare un buon posto, ma forse una farmacia.

Giovanni: E tu, Paolo?

Paolo: Io e la mia fidanzata e poi qui a Milano per un po' è più tranquilla. a vivere in Svizzera insieme, perchè lì la vita

\section{Riordina il dialogo tra Silvia e Alberto:}

B1: $\quad / 10$

1 Ehi Alberto, cosa farai la prossima estate?

2 Ancora non lo so, probabilmente resterò tutta l'estate a Rimini. È quello che ho detto anch'io, ma prova tu a spiegarlo a Laura!

Oddio no! I tour organizzati sono noiosissimi.

Esatto. Forse se parlerà con Rossana, Laura si convincerà. Ma non volevi fare un viaggio all'estero?

Perchè non le dici di parlare con Rossana e Tommaso? Hanno fatto un tour organizzato in Egitto e sono rimasti molto delusi.

Perchè? Non le piace viaggiare?

Ah, sì, lo so, gli hanno fatto passare ore ed ore nei negozi con la guida.

Ci provo.

Non credo, Laura ha paura di viaggiare senza guida. Comunque è un'idea. Viaggiare le piace. Il problema è che vuole andare con un tour organizzato.

Sì, volevo andare in Turchia, ma con Laura è impossibile. 


\section{Completa con la parola adeguata:}

B1: 17

B2: $/ 10,5$

1. A un di lavoro non dovete rispondere alle domande che riguardano la sfera personale: lo stato , la gravidanza, l'orientamento religioso ecc.

2. Se volete fare un viaggio in macchina fuori dall'Europa, controllate prima se dovete avere la internazionale di guida.

3. Il mio di lavoro è di 40 ore settimanali.

4. Ho cominciato a lavorare tre mesi dopo il parto, però a tempo , cioè solo quattro ore al girno.

5. Silvia oggi ha firmato un nuovo di lavoro ed è contentissima perchè finalmente le hanno dato l'aumento di

\section{Prilog II}

Tabela 1

\begin{tabular}{|c|c|c|c|}
\hline \multicolumn{2}{|c|}{} & Aritmetička sredina (M) & Standardna devijacija \\
\hline \multirow{2}{*}{ Par 1 } & gramatika A &, 713 &, 2500 \\
\cline { 2 - 4 } & gramatika B1 &, 619 &, 2774 \\
\hline \multirow{2}{*}{ Par 2 } & razumevanje A &, 884 &, 2099 \\
\cline { 2 - 4 } & razumevanje B1 &, 610 &, 3709 \\
\hline \multirow{2}{*}{ Par 3 } & leksika A &, 668 &, 1859 \\
\cline { 2 - 4 } & leksika B1 &, 41 &, 309 \\
\hline \multirow{2}{*}{ Par 4 } & gramatika A &, 713 &, 2500 \\
\cline { 2 - 4 } & gramatika B2 &, 6800 &, 25431 \\
\hline \multirow{2}{*}{ Par 5 } & razumevanje A &, 884 &, 31924 \\
\cline { 2 - 4 } & razumevanje B2 &, 6484 &, 1850 \\
\hline \multirow{2}{*}{ Par 6 } & leksika A &, 668 &, 44800 \\
\cline { 2 - 4 } & leksika B2 &, 6161 & \\
\hline
\end{tabular}


Dragana Ž. Mirčić Panić

Tabela 2

\begin{tabular}{|c|c|c|c|c|c|c|}
\hline \multicolumn{2}{|c|}{} & $\begin{array}{c}\text { Aritmetička } \\
\text { sredina (M) }\end{array}$ & $\begin{array}{c}\text { Standardna } \\
\text { devijacija }\end{array}$ & t- vrednost & $\begin{array}{c}\text { Stepeni } \\
\text { slobode } \\
\text { (df) }\end{array}$ & $\begin{array}{c}\text { Značajnost } \\
\text { (p) }\end{array}$ \\
\hline Par 1 & $\begin{array}{c}\text { gramatika A } \\
\text { gramatika B1 }\end{array}$ &, 0935 &, 2308 & 2,256 & 30 &, 031 \\
\hline Par 2 & $\begin{array}{c}\text { razumevanje A } \\
\text { razumevanje B1 }\end{array}$ &, 2742 &, 2594 & 5,884 & 30 &, 000 \\
\hline Par 3 & $\begin{array}{c}\text { leksika A } \\
\text { leksika B1 }\end{array}$ &, 2535 &, 2778 & 5,080 & 30 &, 000 \\
\hline Par 4 & $\begin{array}{c}\text { gramatika A } \\
\text { gramatika B2 }\end{array}$ &, 03287 &, 22824 &, 802 & 30 &, 429 \\
\hline Par 5 & $\begin{array}{c}\text { razumevanje A } \\
\text { razumevanje B2 }\end{array}$ &, 23548 &, 22143 & 5,921 & 30 &, 000 \\
\hline Par 6 & $\begin{array}{c}\text { leksika A } \\
\text { leksika B2 }\end{array}$ &, 04911 &, 39518 &, 703 & 30 &, 487 \\
\hline
\end{tabular}

\section{Tabela 3}

\begin{tabular}{|l|c|c|c|}
\hline & A & B1 & B2 \\
\hline gramatika & $71 \%$ & $62 \%$ & $68 \%$ \\
\hline razumevanje & $88 \%$ & $61 \%$ & $69 \%$ \\
\hline leksika & $67 \%$ & $41 \%$ & $41 \%$ \\
\hline
\end{tabular}

